\title{
ROBOTIC ROUX-EN-Y GASTRIC BYPASS: OPERATIVE RESULTS IN 100 PATIENTS
}

\author{
Bypass gástrico em Y-de-Roux por via robótica: resultados de 100 pacientes operados
}

Carlos Eduardo DOMENE, Paula VOLPE, Frederico A. HEITOR

From the NUTRO - Núcleo Unificado de Tratamento do Obeso (Unified Nucleus for Treatment of the Obese), São Paulo, SP, Brazil.

HEADINGS - Obesity surgery. Robotic surgery. Roux-en-Y gastric bypass.
ABSTRACT - Background - Laparoscopic gastric bypass is gold-standard for morbid obesity treatment. $\boldsymbol{A i m}$ - To describe the results of robotic gastric bypass for morbid obesity patients. Method - Were operated on 100 morbidly obese patients through totally robotic gastric bypass between 2013 and 2014. They were 83\% female. The age ranged from 20 to 65 years old (medium 48,5 years); the body mass index varied between 38-67 (medium 42,3 kg/ $\mathrm{cm}^{2}$ ). The procedure was designed with $3 \mathrm{~cm}$ long gastric pouch, $1 \mathrm{~m}$ biliopancreatic limb, 1,2 $\mathrm{m}$ alimentary limb, manual or stapled anastomosis. There were four super-super-obese patients and four revisional surgeries. Results - Docking time varied from 1 to 20 min (medium 4 $\mathrm{min}$ ). Console time varied from 40-185 min (medium $105 \mathrm{~min}$ ). There were no intra operative complications or mortality. There were two lower limb deep venous thrombosis. There was no readmission in the first 30 days. Conclusion - Totally robotic gastric bypass is safe and reproduceable, with excellent results even during the initial experience with regular surgeries, revisional surgeries or in super-obese patients. Adequate training may shortens or obviates the learning curve.

\author{
Correspondence: \\ Carlos Eduardo Domene \\ E-mail: cedomene@terra.com.br \\ Financial source: none \\ Conflicts of interest: none
}

Received for publication: 21/01/2014

Accepted for publication: 22/04/2014

DESCRITORES - Cirurgia da obesidade. Cirurgia robótica. Bypass gástrico em Y-de-Roux
RESUMO - Racional - O bypass gástrico laparoscópico é operação consagrada no tratamento da obesidade mórbida. Objetivo - Apresentar resultados da cirurgia robótica na realização do bypass gástrico para controle da obesidade mórbida. Método - Foram operados 100 pacientes com obesidade mórbida totalmente por via robótica entre 2013 e 2014. Dos pacientes 83\% eram mulheres. A idade variou de 20-65 anos (média de 48,5 anos). $O$ índice de massa corpórea variou entre 38-67 (média de 42,3 kg/cm²). O modelo da operação constou de um coto gástrico de $3 \mathrm{~cm}$ de extensão, alça biliopancreática de $1 \mathrm{~m}$, alça alimentar de 1,2 m, anastomose manual ou com grampeador linear. Quatro pacientes eram super-super-obesos, e houve quatro casos de operações revisionais. Resultados - O tempo de acoplamento do robô variou de 1 a 20 min, com média de 4. O tempo de console variou de 40 a 185 min, com média de 105. Não houve complicações intra-operatórias. Houve duas tromboses venosas profundas de membros inferiores. Não houve mortalidade ou re-internação nos primeiros 30 dias. Conclusão - O bypass gástrico robótico mostrou-se seguro e apresentou excelentes resultados mesmo na fase inicial da experiência nas operações primárias, revisionais e em pacientes super-obesos. Adequado treinamento pode encurtar ou obviar a curva de aprendizado.

\section{INTRODUCTION}

aparoscopic Roux-en-Y gastric bypass, in its various versions - as the size of the gastric stump, anastomotic diameter, shape of anastomosis, extension of food and biliopancreatic loops, use or no use of constriction ring - is still the procedure of election to help control morbid obesity ${ }^{17}$. More recently, the operation called robotics - performing laparoscopic surgery using robotic arms controlled remotely by the surgeon - was proposed as an evolution of conventional laparoscopy, and is being evaluated in performing the gastric bypass.

The objective of this paper is to present the results of the initial 100 cases of patients operated between 2013 and 2014, with totally robotic approach analyzing demographic data, length of docking time, console time, learning curve, time of hospitalization, immediate complications and re-admissions in the immediate postoperative period.

\section{METHOD}

One hundred non consecutive patients suffering from morbid obesity were operated. The selection between laparoscopic and robotic approach was based on patient choice and access to robotic platform without randomization. Eighty-three patients were women (83\%), aged 20-65 years (mean 48.5), body mass index (BMI) between 38-67 (mean 42.3). They underwent Roux-en-Y gastric bypass totally robotic. The model of operation consisted of a $3 \mathrm{~cm}$ gastric pouch, biliopancreatic loop of $1 \mathrm{~m}$, feed loop of $1.2 \mathrm{~m}$, manual anastomosis or a linear stapler.

Two of the authors (CED and PV) had extensive prior training, consisting of theoretical learning, training on dry and wet lab, edited videos visualization, live 
assistance to operations, training simulator for more than $40 \mathrm{~h}$ before the first procedure and supervision in the first 20 operations done by an enabled robotic bariatric surgeon.

\section{RESULTS}

All operations were done in fully robotic way, without any conversion. The docking time of the robotic platform is shown in Figure 1.

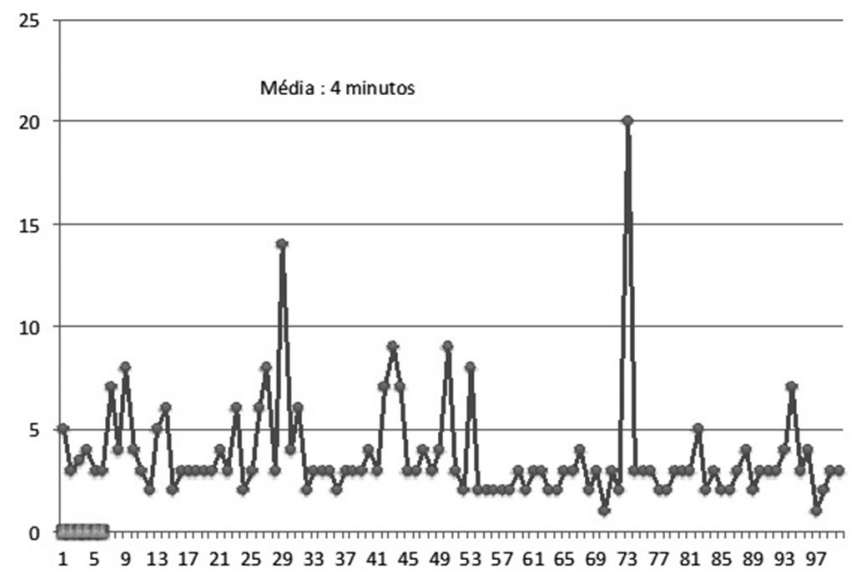

FIGURE 1 - "Docking time"

The adaptation of the robotic arms to the trocars, performed by the surgeon and the assistant, varied between 1 and 20 min, and proved to be practically constant since the beginning, with 15 cases in which there was no more than 5 min delay for docking, almost uniformly distributed during the period, tending to remain below 4 min after about 50 cases; in most cases this time was even lower than 4 min.

The console time of the surgeon (Figure 2 ) ranged from 40 min (one patient) to 185 minutes (one patient), with a mean time of $105 \mathrm{~min}$. In the first 30 patients tended to be between 60 and $135 \mathrm{~min}$; thereafter decreased between 50-80 min. There was consistent and progressive decrease in the average operating time with increasing experience.

\section{tempo de console}

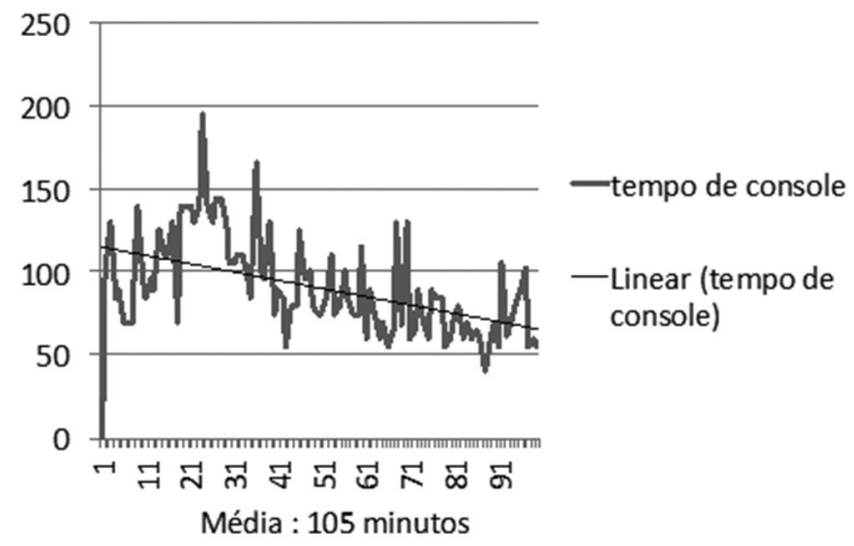

\section{FIGURE 2 - Console time}

There were no intraoperative complications but only two minor in the immediate postoperative period: two patients had deep venous thrombosis of in the lower limbs. These occurrences were unrelated to age, risk factors for thrombosis, medication use, operation time or prolonged immobilization, and occurred in case number 35 and 67.

Patients were free to eat in the next morning and released from hospitalization in $24 \mathrm{~h}$ or less. None needed to remain more than $24 \mathrm{~h}$ in the hospital. There were no leaks or fistulas. There was no postoperative mortality. There was no re-admission within 30 days postoperatively. Four patients previously operated on for morbid obesity were re-operated for complications or poor results of previous bariatric operation. In these revisional operations, the immediate postoperative course was similar to the conventional procedure, regardless of the complexity of the revisional operation. Four patients were super-obese, and the operation was performed safely and comfortably in them all; operation was not prolonged for this reason.

\section{DISCUSSION}

Bariatric surgery has evolved significantly over the past 20 years. Complications decreased and the leaks and fistulas occur in less than $0.5 \%$ of cases ${ }^{12}$. Conversion rates, bleeding, fistulas or leaks from anastomoses and immediate re-operations are currently very low ${ }^{15}$. Bariatric surgery has achieved the level of excellence through progressive learning with the standardization and systematization of the operative procedure, and the best results obtained in high-volume services ${ }^{7}$.

The robotic surgery - laparoscopic surgery with the aid of mechanical arms with remote control - brought new perspectives ${ }^{22}$. The three dimensional robotic vision, coupled with the precision of movements and the degree of freedom of the robotic grippers, brought new approaches for more complex laparoscopic operations ${ }^{10}$. It has several advantages in patients with very thick abdominal wall, large amount of intra-abdominal fat, limited space for pneumoperitoneum, very large livers, small and difficult to access operative field. These facts may prolong procedure demanding great performance and requiring great physical strength of the surgical team, decreasing the precision of movements. The robotic platform has features that would bring advantages and solutions to these dificulties ${ }^{6}$. The robotic arms are fixed and offer constant traction without the need of force by the surgeon. The puncture point of the abdominal wall is stable, and the arm rotates around this point, not exerting any force on the wall; by contrary, allows further lifting and increase the abdominal cavity by trocar drift coupled with the longer arm, catching a few inches up. Space can be larger than the laparoscopic field, and much more stable without the need to exert force in manipulating the instruments. These features assist in performing the procedure with precision and certainty. The three-dimensional view and high image magnification allows the surgeon to operate on tiny operative field operative even in small spaces. The fixed camera and the stable arm also help determine safety and accuracy. However, this characteristic of the positioning and fixing of the robot may be responsible for a greater number of postoperative hernias of the trocars sites ${ }^{17}$.

All these differences favoring the robot could determine the achievement of better results than with conventional laparoscopic bariatric surgery. However, analysis of case series, systematic or comparative reviews, have difficulty in proving significant advantage of the robot over conventional laparoscopy. One of the reasons is that the current laparoscopic treatment has low morbidity and mortality, necessitating very large number of patients to obtain significant results².

Prospective studies comparing robotic and laparoscopic gastric bypass demonstrated equal ${ }^{11,12,14}$ or better results with robot $^{4,13}$. In a study was made comparison of robotic initial series with the previously performed laparoscopic series, showing higher immediate complications and longer hospitalization in the robotic series ${ }^{3}$.

The analysis of these studies requires assessment to the so called learning curve, which can influence the 
results and is difficult to be compared. All groups that started series of robotic operations had extensive prior experience with laparoscopy, ie, great proficiency in laparoscopy before initiating the use of the robot. There is a clear tendency that studies, even though prospective, with this design, favoring the procedure in which the surgeon has greater familiarity, in this case laparoscopy. Comparative analysis with less chance of error, but difficult to implement, would be starting at the same time: experience with laparoscopy and robotics; evidently this study will be almost impossible to accomplish. In addition, the learning curve for robotic surgery has many variables, making it difficult to compare even between different learning curves. Some studies show curve rather shorter; however, in all these studies the surgeons were already proficient in laparoscopy, which greatly helps the robotic learning ${ }^{1,8,9,16,19}$. Overcoming the learning curve - defined in the expression of shorter operative time and fewer complications - varies greatly among authors, set between eight and 84 procedures. The shift of the curve after eight operations ${ }^{1}$ is within a scenario of average docking time of $8.5 \mathrm{~min}$ and console of $187 \mathrm{~min}$; in the present study these average times were 4 and $105 \mathrm{~min}$.

The type, extent and intensity of previous training decisively influence the performance of the learning curve. The current scheme - theory, dry laboratory and animal in two days, observation and supervision of cases in the first five operations - seems insufficient to start a low rate of minor complications and operative times, even for surgeons with expertise in laparoscopy. In this series, the docking time was uniformly low from the start of the experiment (Figure 1). This contributed to the standardization of positioning of the trocars and the robotic car, and this was the same procedure in all cases. There was a trend of gradual and uniform decrease of the average time (Figure 1). These times were still considerably shorter than the average reported in the literature: only one operation lasted 185 minutes; most ranged from 50-100 min, less than laparoscopic surgeons for the same procedure including the initial phase of robotic time series. It is possible that the type of training performed by surgeons (CED and PV) has influenced the achievement of good results: theoretical training, training in wet and dry laboratory, observation of numerous operations, simulator training for more than $40 \mathrm{~h}$ and 20 supervised procedures with extensive and intensive preparation of nursing staff and clinical engineering. The good results obtained with these training models ${ }^{15}$ may suggest that the learning curve can be very short, or does not exist, if there is institutional commitment to the whole process. Prolonged supervision favors learning of ingenious and creative solutions to particular situations that happen in significant number of operations.

The use of the robotic platform can also be favorable in special situations, such as super-obesity ${ }^{6}$ and revisional operations $\mathbf{s}^{5,20}$, and in addition facilitates the realization of anastomoses ${ }^{7}$. Super-obese patients are operated in a similar manner to those with lower BMI, given the ability to operate in very small visual field, prime and stable view of the operative field, smooth motion due to the stability of the robotic arms, which do not require any physical effort by the team ${ }^{6}$. In this series there were four super-super obese patients who had their procedure performed safely, with good ergonomy in operative time similar to other procedures and equal postoperative course.

The inside view, in three dimensions, stable and very close to the surgical field associated with the delicacy of the clamps and movement of the robotic arms (arm movements are scaled relative to the magnitude of external movement, according to the needs of each procedure), allows very precise dissection of anatomical structures, facilitating the identification of the re-operations plans. The revisional operations become safer when the platform is used ${ }^{18}$. The four revisions in this series were held in operative time nearly equal to the primary operations with equal postoperative course. Robotic surgery makes performing gastric bypass in cases of primary surgery, revisional or super-obese patients due to the stability of operative field, proper ergonomy and optimal viewing in all procedures. Anastomoses, mainly gastrojejunal, are better visualized and executed with greater stability and security; these features may justify the difference in outcome compared to laparoscopy. The use of future digital resources is only possible in robotic surgery, for identifying ischemic areas in the gastric pouch and intestinal loop, what can theoretically contribute to the reduction of leaks. Proper training reduces or abolishes the learning curve for robotic in surgeons with experience in laparoscopy. Stability characteristics, unique insight and precision of movements should facilitate obtaining good results in super-obese patients and revisional operations.

CONCLUSION

Totally robotic gastric bypass is safe and reproduceable, with excellent results even during the initial experience with regular surgeries, revisional surgeries or in super-obese patients. Adequate training may shortens or obviates the learning curve.

\section{REFERENCES}

1. Ayloo S, Fernandes E, Choudhury N - Learning curve androbotsetup/operative times in singlydockedtotallyroboticRoux-en-Y gastric bypass. SurgEndosc 2014;28(5):1629-33

2. Bailey JG, Hayden JA, Davis PJ, Liu RY, Haardt D, Ellsmere J - Robotic versus laparoscopicRoux-en-Y gastric bypass in obeseadults ages 18 to 65 years: a systematicreviewandeconomicanalysis. SurgEndosc 2014;28(2):414-26

3. Benizri EI, Renaud M, Reibel N, Germain A, Ziegler O, Zarnegar R, Ayav A, Bresler L, Brunaud L Perioperativeoutcomesaftertotallyroboticgastric bypass: a prospectivenonrandomizedcontrolledstudy. Am J Surg 2013;206(2):145-51

4. Buchs NC, Morel P, Azagury DE, Jung M, Chassot G, Huber O, Hagen ME, Pugin F - Laparoscopic versus roboticRoux-en-Y gastric bypass: lessonsandlong-term follow-up learnedfrom a largeprospectivemonocentricstudy. ObesSurg 2014;24(9):1245-51

5. Buchs NC, Pugin F, Azagury DE, HuberO, Chassot G, MorelP-Robotic revisionalbariatricsurgery:a comparativestudywithlaparoscopicand open surgery. Int J MedRobot 2014;10(2):213-7

6. Buchs NC, Pugin F, Chassot G, Volonte F, Koutny-Fong P, Hagen $M E$, Morel $P$ - Robotic-assistedRoux-en-Y gastric bypass for superobesepatients: a comparativestudy. ObesSurg 2013;23(3):353-7

7. Cirocchi R, Boselli C, Santoro A, Guarino S, Covarelli P, Renzi C, Listorti C, Trastulli S, Desiderio J, Coratti A, Noya G, Redler A, Parisi A - Current status ofroboticbariatricsurgery: a systematicreview. BMC Surg 2013;13:53-60

8. Fort JM, Vilallonga R, Lecube A, Gonzalez O, Caubet E, Mesa J, Armengol M - Bariatricsurgeryoutcomes in a European Centre ofExcellence. ObesSurg 2013;23(8):1324-32

9. Fourman MM, Saber AA - Roboticbariatricsurgery: a systematicreview. SurgObesRelatDis 2012;8(4):483-8

10. KimK, HagenME, BuffingtonC-Roboticsinadvancedgastrointestinal surgery: thebariatricexperience. Cancer J 2013;19(2):177-82

11. Markar SR, Karthikesalingam AP, VEnkat-Ramen V, Kinross J, Ziprin P - RoboticvslaparoscopicRoux-en-Y gastric bypass in morbidlyobesepatients: systematicreviewandpooledanalysis. Int J MedRobot 2011;7(4):393-400

12. Markar SR, Penna M, Hashemi M - Roboticbariatricsurgery: bypass, bandorsleeve. Where are wenow? Andwhatisthe future? Minerva GastroenterolDietol 2012;58(3):181-90

13. Myers SR, McGuirl J, Wang J - Robot-assisted versus laparoscopicgastric bypass: comparisonof short-termoutcomes. ObesSurg 2013;23(4):467-73

14. Park CW, Lam EC, Walsh TM, Karimoto M, Ma AT, Koo M, Hammill C, Murayama K, Lorenzo CS, Bueno R - Robotic-assistedRoux-en-Y gastric bypass performed in a community hospital setting: the future ofbariatricsurgery? SurgEndosc 2011;25(10):3312-21 
15. Ramos AC, Domene CE, Volpe P, Pajecki D, D'Almeida LA, Ramos MG, Bastos EL, Kim KC - EarlyoutcomesofthefirstBrazilianexperience in totallyroboticbariatricsurgery. ArqBrasCirDig 2013; 26 Suppl 1:2-7 16. Renaud M, Reibel N, Zarnegar R, Germain A, Quilliot D, Ayav A, Bresler $L$, Brunaud $L$ - Multifatorial analysisofthelearning curve for totallyroboticRoux-en-Y gastric bypass for morbidobesity. ObesSurg 2013;23(11):1753-60

17. Scozzi G, Zanini M, Cravero F, Passera R, Rebecchi F, Morino M. High incidenceof trocar site hérnia afterlaparoscopicorroboticRoux-en-Y gastric bypass. SurgEndosc 2014; 28(5):620-8

18.Snyder B, Wilson T, Woodruff V, Wilson E Roboticallyassistedrevisionofbariatricsurgeriesis safe andeffectivetoachievefurtherweightloss. World J Surg 2013;37(11):2569-73
19.Sudan R, Bennett KM, Jacobs DO, Sudan DL Multifactorialanalysisofthelearning curve for robot-assistedlapa roscopicbiliopancreaticdiversionwith duodenal switch. Ann Surg 2012;255(5):940-45

20. Tieu K, Allison N, Snyder B, Wilson T, Toder M, Wilson E - RoboticassistedRoux-en-Y gastric bypass: updatefrom 2 high-volume centers. SurgObesRelatDis 2013;9(2):284-8

21. Toro JP, Lin E, Patel AD - Reviewofrobotics in foregutandbariatricsurgery. SurgEndosc 2014; 28(6):721-9

22. Wilson EB, Sudan R-The evolutionofroboticbariatricsurgery. World J Surg 2013;37(12):2756-60 